\title{
AN AERIAL RADIOLOGICALSURVEY OF THE PROJECT RIO BLANCO AND SURROUNDING AREA
}

\author{
NORTHWESTERN COLORADO
}

DATE OF SURVEY: JUNE 1993

L. V. Singman

Project Scientist

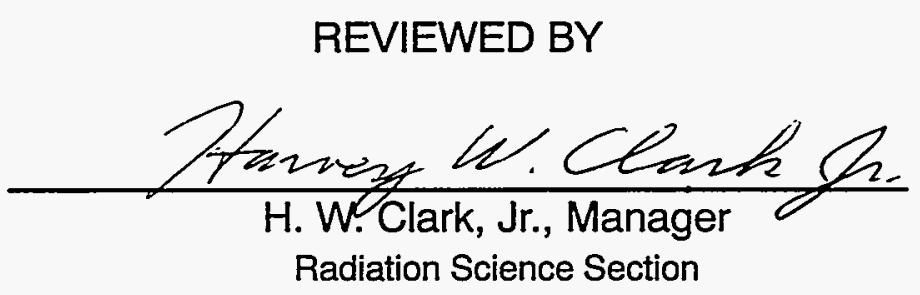

This Document is UNCLASSIFIED
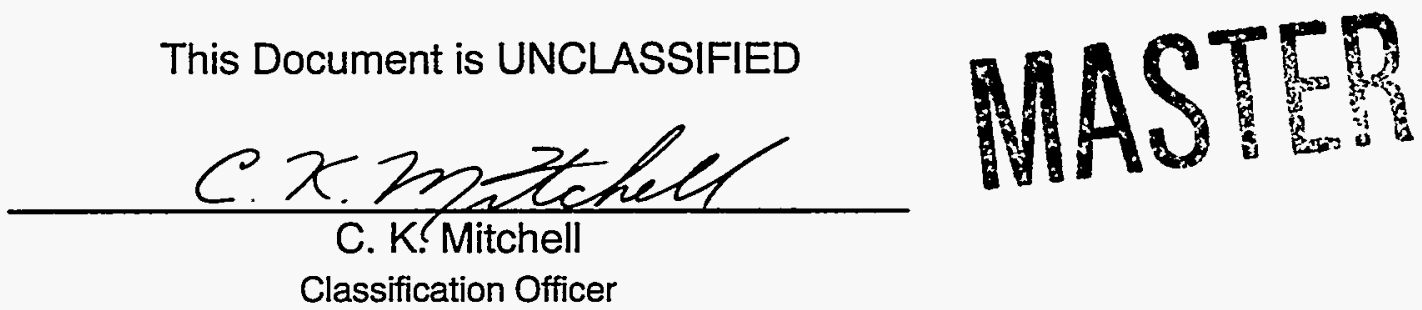

Classification Officer

This work was performed by EG\&G/EM for the United States Department of Energy under Contract Number DE-AC08-93NV11265. 


\section{DISCLAIMER}

This report was prepared as an account of work sponsored by an agency of the United States Government. Neither the United States Government nor any agency thereof, nor any of their employees, make any warranty, express or implied, or assumes any legal liability or responsibility for the accuracy, completeness, or usefulness of any information, apparatus, product, or process disclosed, or represents that its use would not infringe privately owned rights. Reference herein to any specific commercial product, process, or service by trade name, trademark, manufacturer, or otherwise does not necessarily constitute or imply its endorsement, recommendation, or favoring by the United States Government or any agency thereof. The views and opinions of authors expressed herein do not necessarily state or reflect those of the United States Government or any agency thereof. 


\section{DISCLAIMER}

Portions of this document may be illegible in electronic image products. Images are produced from the best available original document. 


\section{ABSTRACT}

A team from the Remote Sensing Laboratory in Las Vegas, Nevada, conducted an aerial radiation survey of the area surrounding ground zero of Project Rio Blanco in the northwestern section of Colorado in June 1993. The object of the survey was to determine if there were man-made radioisotopes on or near the surface resulting from a nuclear explosion in 1972.

No indications of surface contamination were found. A search for the cesium-137 radioisotope was negative. The Minimum Detectable Activity for cesium-137 is presented for several detection probabilities. The natural terrestrial exposure rates in units of Roentgens per hour were mapped and are presented in the form of a contour map overlaid on an aerial photograph.

A second team made independent ground-based measurements in four places within the survey area. The average agreement of the ground-based with aerial measurements was six percent. 


\section{CONTENTS}

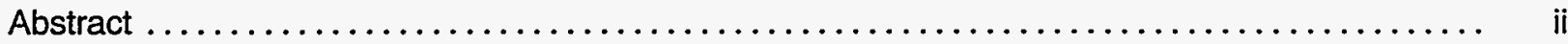

\section{Sections}

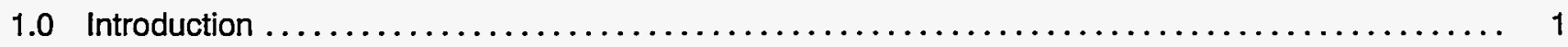

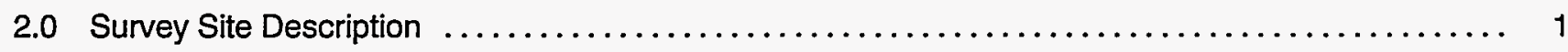

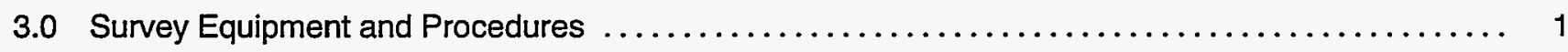

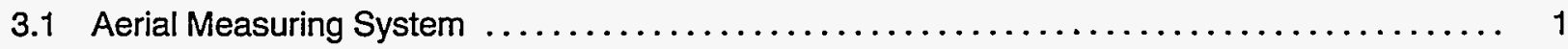

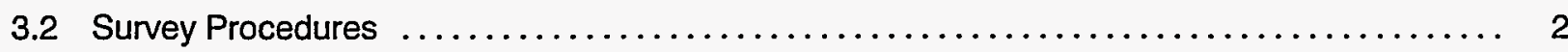

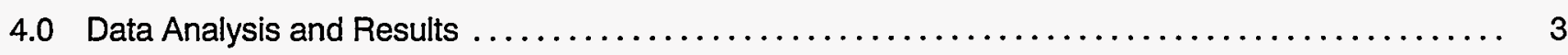

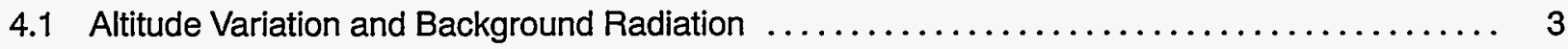

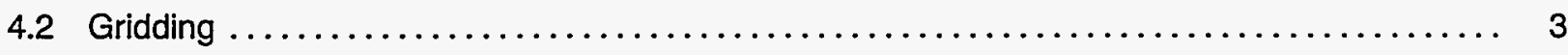

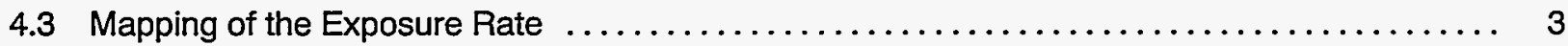

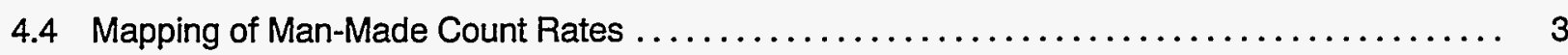

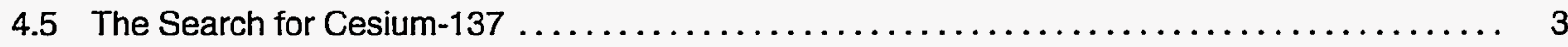

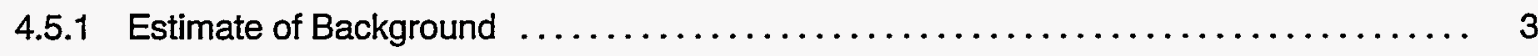

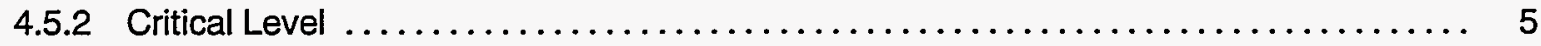

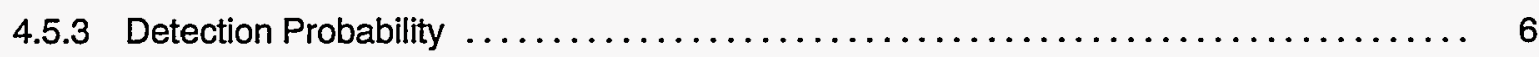

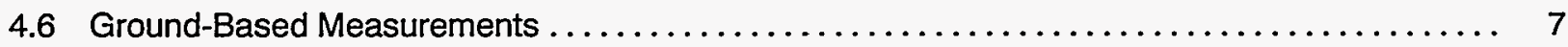

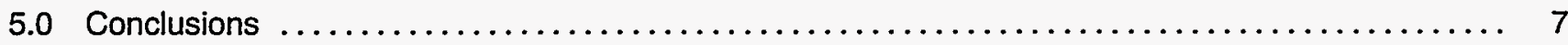

\section{Figures}

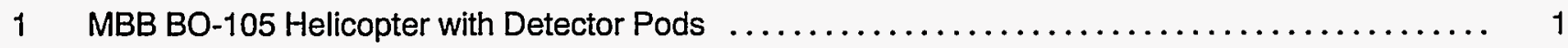

2 Isoradiation Contour Map of Total Gamma Ray Exposure Rates $\ldots \ldots \ldots \ldots \ldots \ldots \ldots \ldots \ldots \ldots$

3 Spectra Measured Inside and Outside the Band of Elevated Activity $\ldots \ldots \ldots \ldots \ldots \ldots \ldots \ldots \ldots$

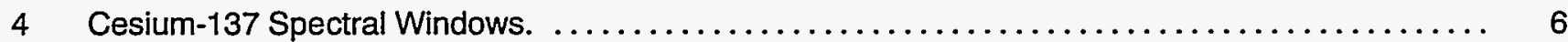

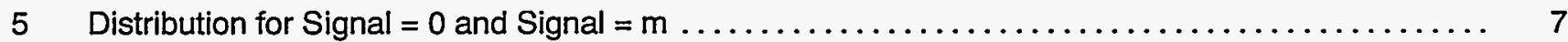

\section{Tables}

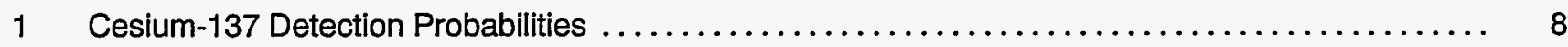

2 Comparison of Aerial and Ground-Based Exposure Rates $\ldots \ldots \ldots \ldots \ldots \ldots \ldots \ldots \ldots \ldots \ldots \ldots$

\section{Appendices}

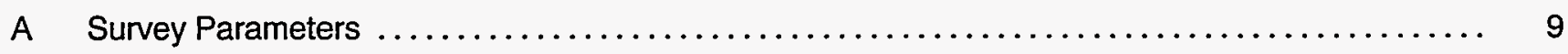

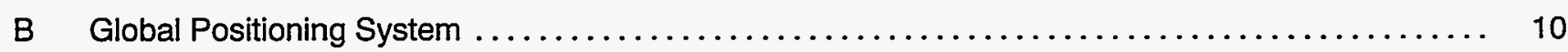

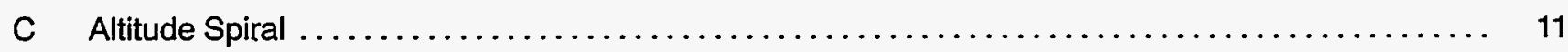

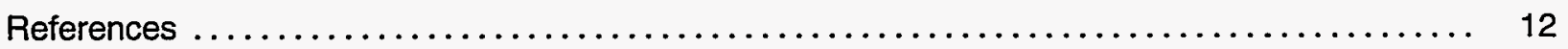




\subsection{INTRODUCTION}

The United States Department of Energy (DOE) maintains an aerial surveillance system, called the Aerial Measuring System (AMS), for the detection of nuclear radiation. The AMS is operated for DOE's Remote Sensing Laboratory (RSL) by EG\&G Energy Measurements, Inc. (EG\&G/EM) and is located at Nellis Air Force Base in Las Vegas, Nevada, and Andrews Air Force Base in Washington, D.C. The AMS is used to ensure public safety from man-made nuclear radiation by monitoring potential sources of radiation such as nuclear power plants, plants manufacturing nuclear materials, and sites of former nuclear detonations.

This survey was conducted in June 1993 to determine if man-made radiation was present at the earth's surface as a result of an underground nuclear detonation in June 1972, code-named Project Rio Blanco. ${ }^{1}$ The detonation was the result of a Plowshare experiment intended to free natural gas from deep rock formations, a project which could not be accomplished economically using conventional technology. Three nuclear explosives were used. They were separated by about $400 \mathrm{ft}$ in the same vertical shaft, the shallowest having been placed a little more than one mile underground. The explosions are estimated to have created more than 200 fission products and left $4 \mathrm{~kg}$ of plutonium behind, all sealed in glazed, underground chambers created by the explosions. ${ }^{2}$ The major participants in the experiment were the CER Geonuclear Corporation of Las Vegas, Nevada, the Lawrence Livermore National Laboratory, and the Atomic Energy Commission.

\subsection{SURVEY SITE DESCRIPTION}

Project Rio Blanco was conducted in the northwest corner of Colorado, 52 miles north of Grand Junction in Rio Blanco County. Ground Zero (GZ) is located in Fawn Creek Valley about eight miles southwest of Rock School on Fawn Creek Road. It is marked by a small cement pedestal with a plaque describing the experiment. The exact location as marked on the plaque is "Latitude: $39^{\circ} 47^{\prime} 34.8^{\prime \prime} \mathrm{N}$, Longitude: $108^{\circ} 21^{\prime} 59.6^{\prime \prime}$ W."2

Fawn Creek runs from southwest to northeast through the center of Fawn Creek Valley. The valley is shallow and flat, about $800 \mathrm{ft}$ wide and bordered by cliffs $100-200 \mathrm{ft}$ high. It is irrigated by Fawn Creek and is used by a local rancher for cattle grazing. The vegetation in the valley is grass in the lower region, and scrub brush and sage in the upper region. The vegetation on the bordering cliffs and ridges is small conifers.

The survey area was a $6-\times 2-\mathrm{mi}(10-\times 3-\mathrm{km})$ rectangle starting one mile above $G Z$, ending five miles below, and extending one mile on either side of Fawn Creek. This placed the majority of the survey area downstream from $G Z$ where any radioactive material was most likely to have migrated. The survey area included part of the Eureka Creek to the west and Little Dry Gulch to the east.

\subsection{SURVEY EQUIPMENT AND PROCEDURES}

\subsection{Aerial Measuring System}

A small, twin-engine Messerschmitt-Bolkow-Blohm (MBB) BO-105 helicopter, shown in Figure 1, carried the radiation detectors over the survey area. Two aluminum pods, each containing four down-looking thallium activitied sodium iodide $\mathrm{Nal}(\mathrm{T} \ell)$ detectors and one up-looking $\mathrm{Nal}(\mathrm{T} \ell)$ detector, were mounted on the skids of the helicopter. A list of the survey parameters may be found in Appendix A.

The function of the down-looking detectors was to measure the terrestrial radiation. The detectors have a large gamma ray-sensitive volume, each detector measuring $2 \times 4 \times 16$ in and oriented with the $4-x$ 16-in face down. The top and the side surfaces were

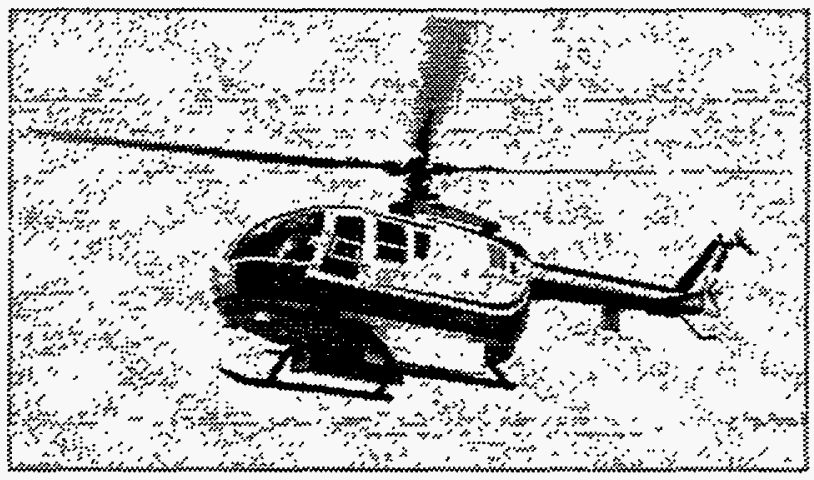

FIGURE 1. MBB BO-105 HELJCOPTER WITH DETECTOR PODS 
lined with $1 / 8$-in lead and 0.040 -in cadmium for shielding against nonterrestrial radiation. (The function of the cadmium was to absorb fluoresced $X$ rays from the lead.) The down-looking face was shielded by the floor of the pod (0.050-in aluminum) and by the hermetically sealed casing for each sodium iodide crystal (0.030-in aluminum). The up-looking detectors were smaller, $2 \times 4 \times 4$ in, and were used to monitor the nonterrestrial radiation.

Gamma signals originating in the eight down-looking detectors were matched in amplitude, combined using summing amplifiers, and fed into an analog-todigital converter (ADC). A second ADC was used to process the gamma signals from one of the eight down-looking detectors as a check of the proper functioning of the system and to increase its dynamic range. The ADCs are components of the Radiation and Environmental Data Acquisition and Recorder System, Model IV (REDAR IV). After conversion, the data were stored in REDAR's memory. Data are sampled at one-second intervals and written on magnetic tape at the end of each four-second period for transfer to a data analysis computer at the end of the flight. The REDAR also processes and stores secondby-second data from various sensors such as atmospheric pressure, outside air temperature, aircraft radar altitude, and position from the Global Positioning System (GPS).

The GPS was used to pair each data point with a position. GPS is a navigational system employing multiple man-made satellites. More detail on the use of the GPS is given in Appendix B.

\subsection{Survey Procedures}

Data acquisition has evolved into a set of routine procedures over the years. These procedures are briefly described here.

Altitude Profile: The nonterrestrial background and a coefficient for the correction of helicopter altitude variations were determined by measuring the count rates when flying the helicopter over the same flight line at six different altitudes ranging from 150 to 3,000 $\mathrm{ft}(46-1,000 \mathrm{~m})$. See Appendix $\mathrm{C}$ for more detail.

Perimeter Flight: The helicopter was flown over landmarks, usually paved roads, in and around the survey area. The purpose of this was to scale the computer-generated plots to maps and photographs by matching the GPS-traced flights on the plots to the landmarks on the maps and photographs.

Test Line: At the beginning of the survey, a test line area was selected outside the survey area, but close to it, to measure variations in the counts due to airborne radon. Before and after each flight, data were collected over the same area. Assuming constant terrestrial activity, any variation in the observed count rate was taken to be due to variations in the atmospheric radon, and the survey data were corrected for it.

Preflight Calibration: Before the first survey flight of the day, the detectors and electronics were allowed to warm up until stable, usually one hour. They were then calibrated using the line spectra of check sources. The calibration was checked before each subsequent flight.

Survey Flights: The data were collected at $150 \mathrm{ft}$ (46 $\mathrm{m})$ above ground level (AGL). At this altitude, the absorption by the air between the ground and the detectors was relatively small for the gamma rays of interest. The helicopter flew along predetermined lines spaced $250 \mathrm{ft}(76 \mathrm{~m})$ apart. The $250-\mathrm{ft}$ line spacing allows complete coverage of the survey area since the detector can "see" out to 45 degrees and beyond permitting a path $300 \mathrm{ft}(100 \mathrm{~m})$ wide to be surveyed for each survey line. The flight lines were parallel to the long dimension of the survey rectangle. This direction is roughly parallel to the altitude contours of the terrain and made it as easy as possible for the helicopter to maintain the 150- $\mathrm{ft}$ altitude. The speed of the helicopter was $70 \mathrm{knots}(36 \mathrm{~m} / \mathrm{s})$. Since data were collected at the rate of one spectrum per second, the radiation contributing to any one spectrum came from an area of approximately elliptical shape, having 300 $\mathrm{ft}(100 \mathrm{~m})$ as its minor diameter and $400 \mathrm{ft}(120 \mathrm{~m})$ as its major diameter. This area is the limit of the spatial resolution of the measurements.

Postflight Checks: Immediately after each flight, a number of checks were made to verify the reliability of the accumulated data. These checks were completed before the next flight departed. Among the items checked were the proper functioning of the detectors, electronics, and instruments. The data were examined for surprises which would change the data acquisition strategy, such as areas of unexpected high intensity radiation.

Serpentine Flight: At the end of the survey, several survey lines from each flight were reflown and the data collected compared to the data from the previous flights. This served as a check on data continuity and reproducibility. 


\subsection{DATA ANALYSIS AND RESULTS}

In analyzing the data, the methods outlined below are routinely used by RSL personnel.

\subsection{Altitude Variation and Background Radiation}

Slight deviations in helicopter altitude make necessary a correction for the varying gamma-ray absorption caused by the changing quantity of air mass between the ground and the helicopter. This correction, along with the correction for cosmic rays, radiation from airborne radon, and the aircraft contribution, was determined by the Altitude Profile and applied to the survey data.

\subsection{Gridding}

The survey area was divided into a $500-\times 500-\mathrm{ft}$ (150- $\times 150-\mathrm{m})$ grid. The measurements within each grid square were averaged and the average assumed to be measured at the center of the square. This improved the statistics of the data, making it more sensitive to man-made sources at the expense of a somewhat degraded spatial resolution.

\subsection{Mapping of the Exposure Rate}

The corrected count rates, summed over the whole Pulse Height Analyzer (PHA) spectrum, were plotted against position to give a contour map of the terrestrial count rate over the survey area. This map of relative activity gives an overview of radiation in the survey area and is useful in indicating the location of radiation sources. However, it is unique to our detection system. To obtain a map of more general use, observed counts were converted to exposure rates (microroentgens/hour) by use of a calibration constant determined periodically over a well-known test area near Lake Mead, Nevada. The resulting exposure rate map is shown in Figure 2.

The map shows a broad diagonal band of increased radioactivity running east-west across the lower valley, shown in Figure 2 in the right third of the survey area. The most. active areas in the band were compared with areas outside the band using spectral analysis. The spectra showed only variations in natural radioactivity. Figure 3 shows two spectra, one taken in a high activity region $(21-23 \mu \mathrm{R} / \mathrm{h}$, Spectrum 1 ) inside the band, the other in a low activity region (15-17 $\mu \mathrm{R} / \mathrm{h}$, Spectrum 2) outside the band.

\subsection{Mapping of Man-Made Count Rates}

The method used to map the count rates due to all man-made radioisotopes is the same as that used for cesium-137 ( $\left.{ }^{137} \mathrm{Cs}\right)$, described in detail below, except for the energy limits of the spectral windows. The spectrum was divided into a low-energy window (less than $1,394 \mathrm{keV}$ ) and a high-energy window (greater than $1,394 \mathrm{keV}$ ). Since almost all gamma rays from man-made radioisotopes have energies below 1,394 $\mathrm{keV}$, the low-energy window was assumed to contain the signal. The high-energy window was used as background.

No outstanding features of man-made radiation were found. The spectra of a few areas were analyzed but showed only natural activity.

\subsection{The Search for Cesium-137}

A review of aerial surveys of Plowshare explosions close to the surface and of a deeply buried explosion which vented (Banebury) showed that ${ }^{137} \mathrm{Cs}$ and cobalt-60 $\left({ }^{60} \mathrm{Co}\right)$ were the main radioactive contaminants detected. ${ }^{3-8}$ Cesium-137 has an appreciably longer half-life than ${ }^{60} \mathrm{Co}$ ( 30 years versus 5.3 years). The ratio of their original activities had changed by about a factor of 10 in favor of ${ }^{137} \mathrm{Cs}$ in the 21 years since Project Rio Blanco, making ${ }^{137}$ Cs the better candidate for detection. Extensive efforts were made to find if any portion of the survey area contained excess amounts of ${ }^{137} \mathrm{Cs}$. (The survey area was expected to contain a small but measurable amount of ${ }^{137} \mathrm{Cs}$ from worldwide fallout.)

\subsubsection{Estimate of Background}

Because of the manner in which the data were collected, it was not possible to establish a well-known background in the conventional way, by repeated measurements. Each measurement was made over a different area with a potentially different natural 


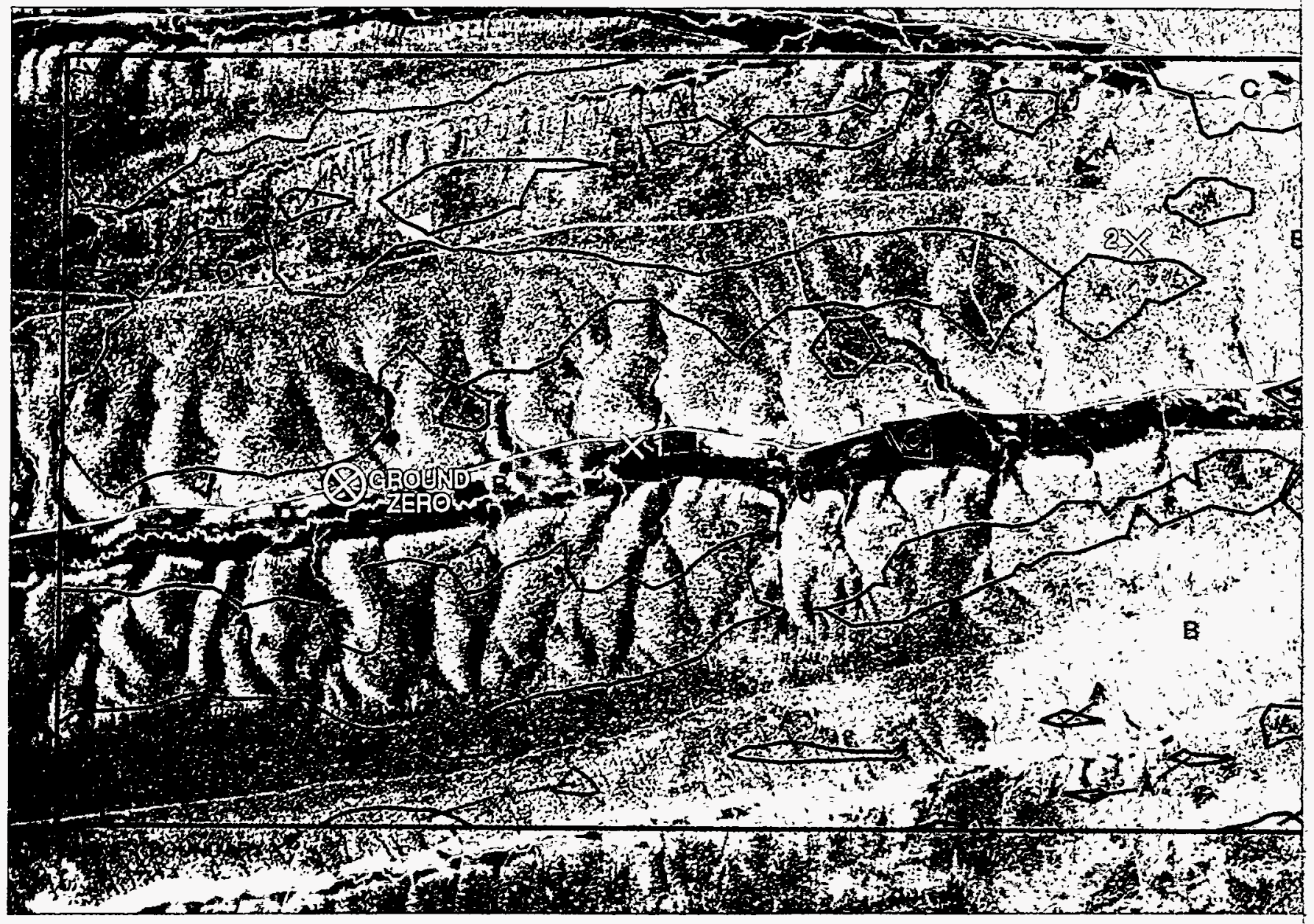

10,000 FEET

3,000 METERS

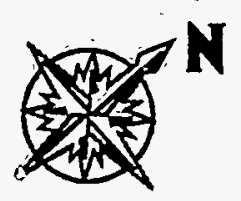

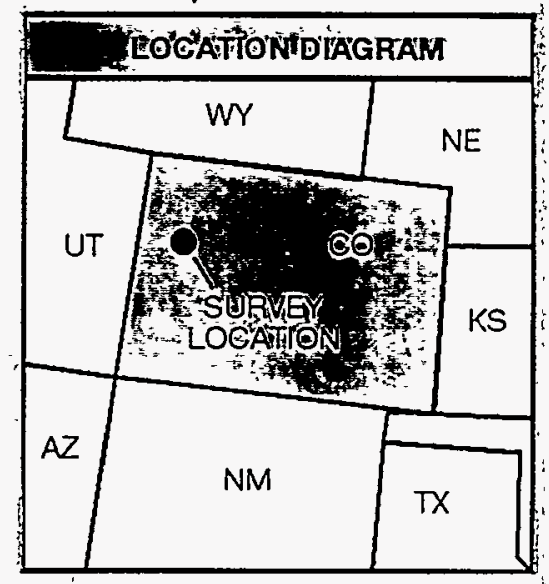

FIGURE 2. ISORADIATION CONTOUR MAP C 


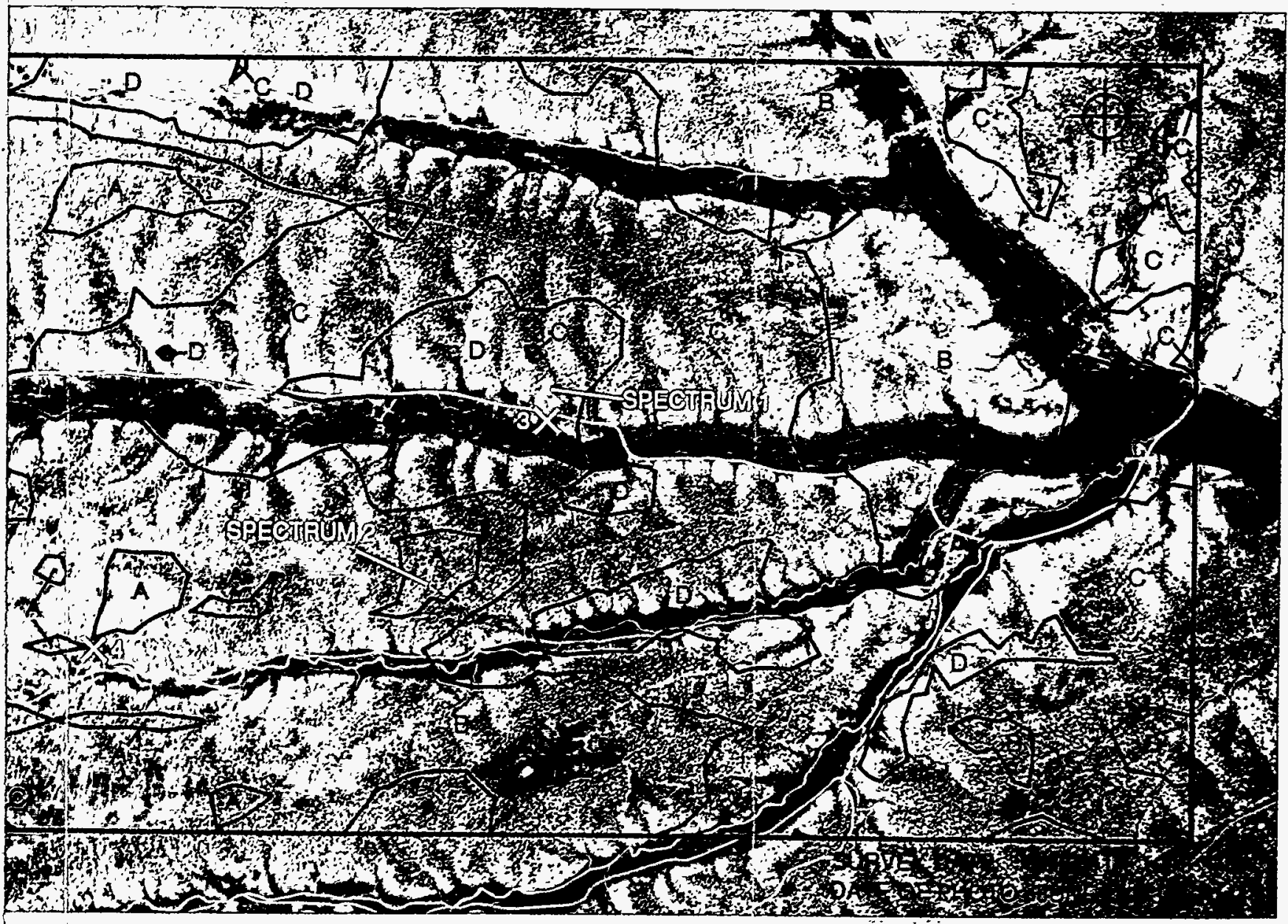

\begin{tabular}{|l|l|}
\hline & LEGEND \\
\hline 1 & $\begin{array}{l}\text { Soil Sample Site } \\
\text { Locations }\end{array}$ \\
\hline
\end{tabular}

\begin{tabular}{|c|c|}
\hline \multicolumn{2}{|c|}{ CONVERSION SCALE } \\
\hline $\begin{array}{c}\text { LETTER } \\
\text { LABEL }\end{array}$ & $\begin{array}{c}\text { EXPOSURE RATE } \\
\text { AT 1 METER }(\mu \mathrm{R} / \mathrm{h})^{*}\end{array}$ \\
\hline A & $15-17$ \\
\hline B & $17-19$ \\
\hline C & $19-21$ \\
\hline D & $21-23$ \\
\hline $\begin{array}{l}\text { *Includes } 7.0 \mu R / h \quad \text { cosmic ray } \\
\text { contribution. } \\
\text { Averaged over } 500 \text { foot squares. } \\
\text { Derived from Aerial Measure- } \\
\text { ments at 150 feet. }\end{array}$ \\
\hline
\end{tabular}




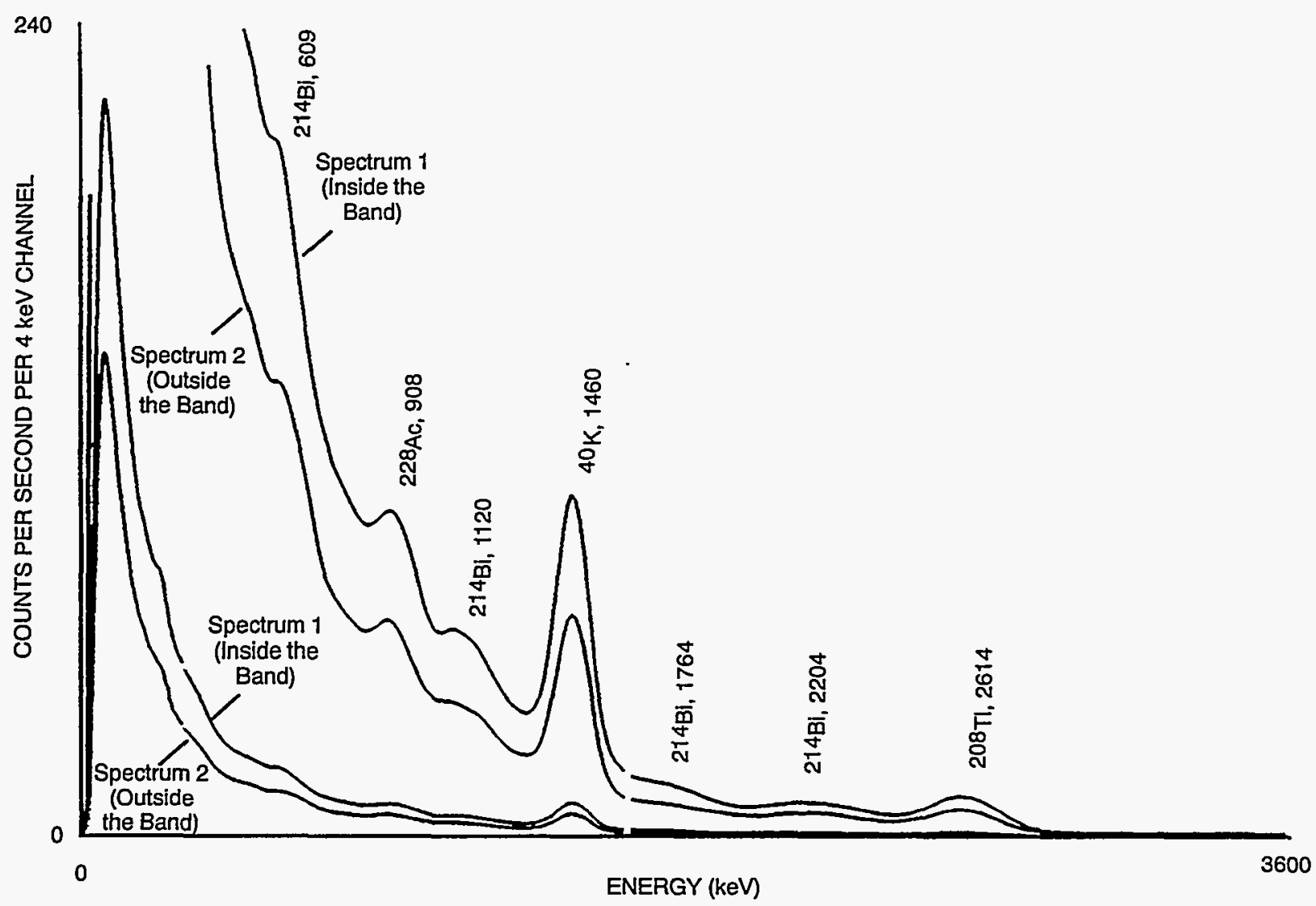

FIGURE 3. SPECTRA MEASURED INSIDE AND OUTSIDE THE BAND OF ELEVATED ACTIVITY. Two curves are shown for each spectrum, differing in scale by 10.

background. However, it was possible to take advantage of the statistical accuracy of the large number of measurements by establishing a "background difference" in each one-second spectrum measured over the test line, where excess ${ }^{137} \mathrm{Cs}$ was absent. Each ${ }^{137} \mathrm{Cs}$ background was estimated from its own onesecond spectrum by the following method.

Three windows were established in each spectrum for the detection of the $662-\mathrm{keV}$ gamma-ray of ${ }^{137} \mathrm{Cs}$ (Figure 4). The central window bracketed the 662-keV peak and served as the signal window with count rate $W$. The two outside windows, with count rates $w 1$ and $w 2$, served to estimate the background in the signal window as $R(w 1+w 2)$. $R$ was taken as the average of the $W /(W 1+W 2)$ values from the 200 test-line measurements. The expression $W-R(w 1+w 2)$ was then evaluated for each one-second measurement to form the test line or the zero signal distribution.

The distribution was assumed to lie on an approximately normal curve since the count rates involved in establishing it exceeded 100 counts per second $(\mathrm{c} / \mathrm{s})^{9}$ (Figure 5). Its standard deviation was calculated from the 200 measurements using the standard expression $\sigma_{0}^{2}=1 /(n-1) \sum_{i=1}^{n}\left(x_{i}-\vec{x}\right)^{2}$, where $x=W-R(w 1$ $+w 2$ ) and $\bar{x}=0$. This calculation was made for each of the 14 test-line measurements, resulting in a standard deviation of $30 \pm 2 \mathrm{c} / \mathrm{s}$, exactly what would be expected on the basis of counting statistics alone (see Figure 4 for count rates).

\subsubsection{Critical Level}

The test-line distribution was used to establish a critical level, $L_{c}$, against which the survey data were compared. ${ }^{10}$ Survey data having values of $W-R(w 1+w 2)$ greater than $L_{c}$ were subjected to spectral analysis for possible ${ }^{137} \mathrm{Cs}$ content. Time would allow only a small fraction of the approximately 12,000 survey measurements to be examined individually. To reduce the number of data points, as well as to improve the statistical accuracy, the data were "gridded," that is, spatially averaged. The grid unit was a 500-ft square, which allowed for 8 or 9 measurements per grid unit. Gridding reduced the number of 


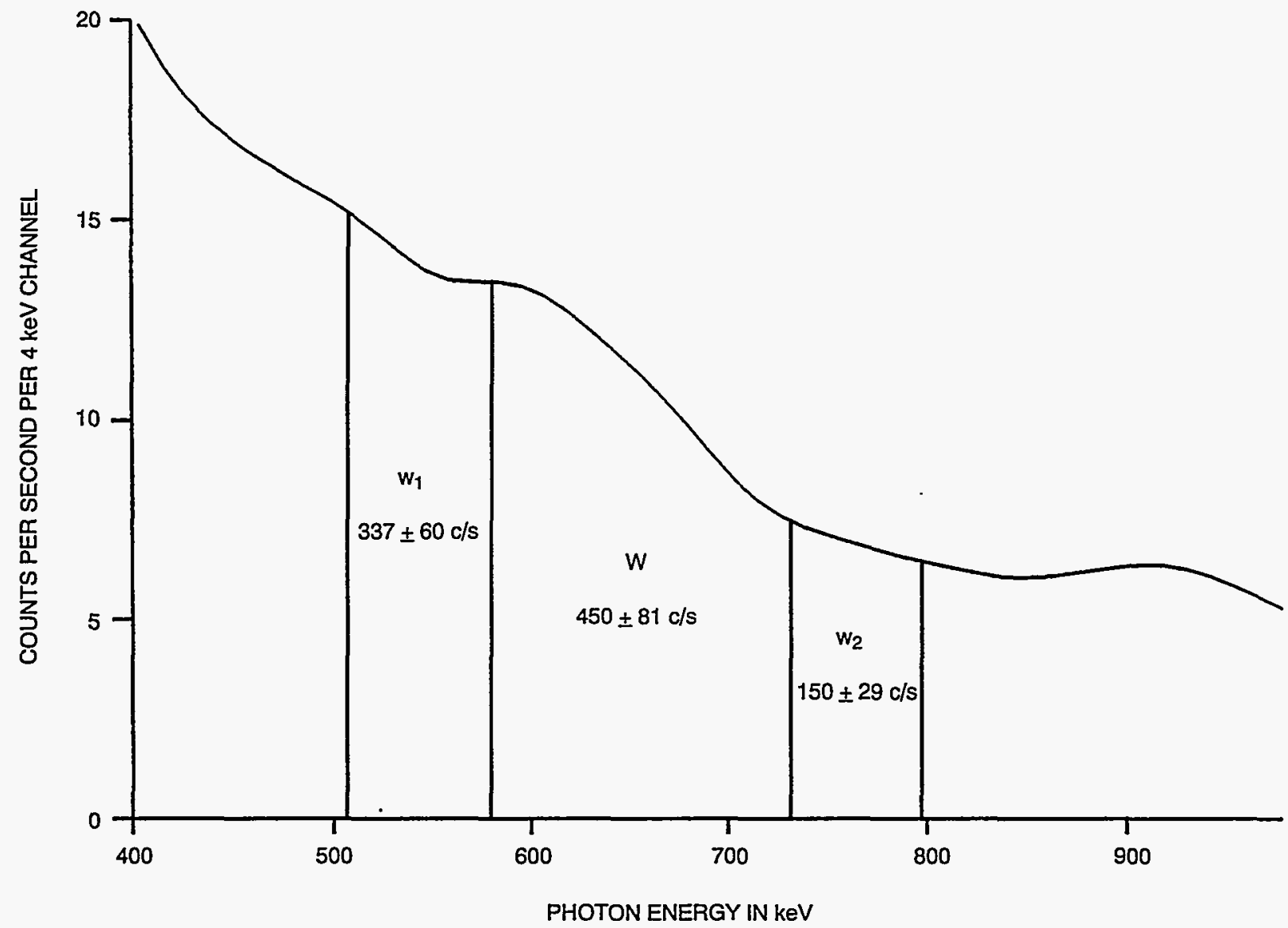

FIGURE 4. CESIUM-137 SPECTRAL WINDOWS. The count rate shown in each window is the average of approximately 200 one-secondmeasurements taken overthe testline plus/minus thestandard deviations. These standard deviationsare several times what would be expected from counting statistics alone, the increase being due to real fluctuations in natural radloactivity.

data points to about 1,400 and decreased the standard deviation of the zero distribution by about a factor of three, from $30 \mathrm{c} / \mathrm{s}$ to $11 \mathrm{c} / \mathrm{s}$, at the expense of a somewhat decreased spatial resolution. Setting $L_{c}=3 \sigma_{0}$ and again assuming a normal zero-signal distribution, the number of data points predicted to exceed $L_{c}$ is $0.13 \%$ of 1,400 or about two. (This predicted number is the minimum which can be expected to exceed $L_{c}$, since only the zero signal distribution was considered.) The actual number of points with count rates exceeding $L_{c}$ was 9 . The disagreement from the predicted number was not surprising, since the fluctuating counts in the $609-\mathrm{keV}$ peak of the bismuth-214 isotope, from variation in the amount of airborne radon would be included in the ${ }^{137} \mathrm{Cs}$ spectral windows. The nine measurements were subjected to individual spectral analysis. No evidence of abnormal counts in the 662-keV peak was found.

\subsubsection{Detection Probability}

The detection probability for a small hypothetical real signal was next predicted. The distribution curve for a mean signal of counts, $m$, is also approximately normal with a standard deviation of the square root of $m$. Since the signal rides on the zero distribution, its distribution curve has to be combined with that of the zero signal distribution curve to obtain a curve which can be observed.

The standard deviation of the combined distribution curve was calculated from $\sigma_{c}^{2}=\sigma_{0}^{2}+m$. (It would seem that $\sigma_{0}^{2}$ and $m$ have different dimensions. However, all statistical quantities have to be regarded as dimensionless. ${ }^{11}$ ) If a detection probability of $90 \%$ is desired, the distribution curve has to be placed so that 


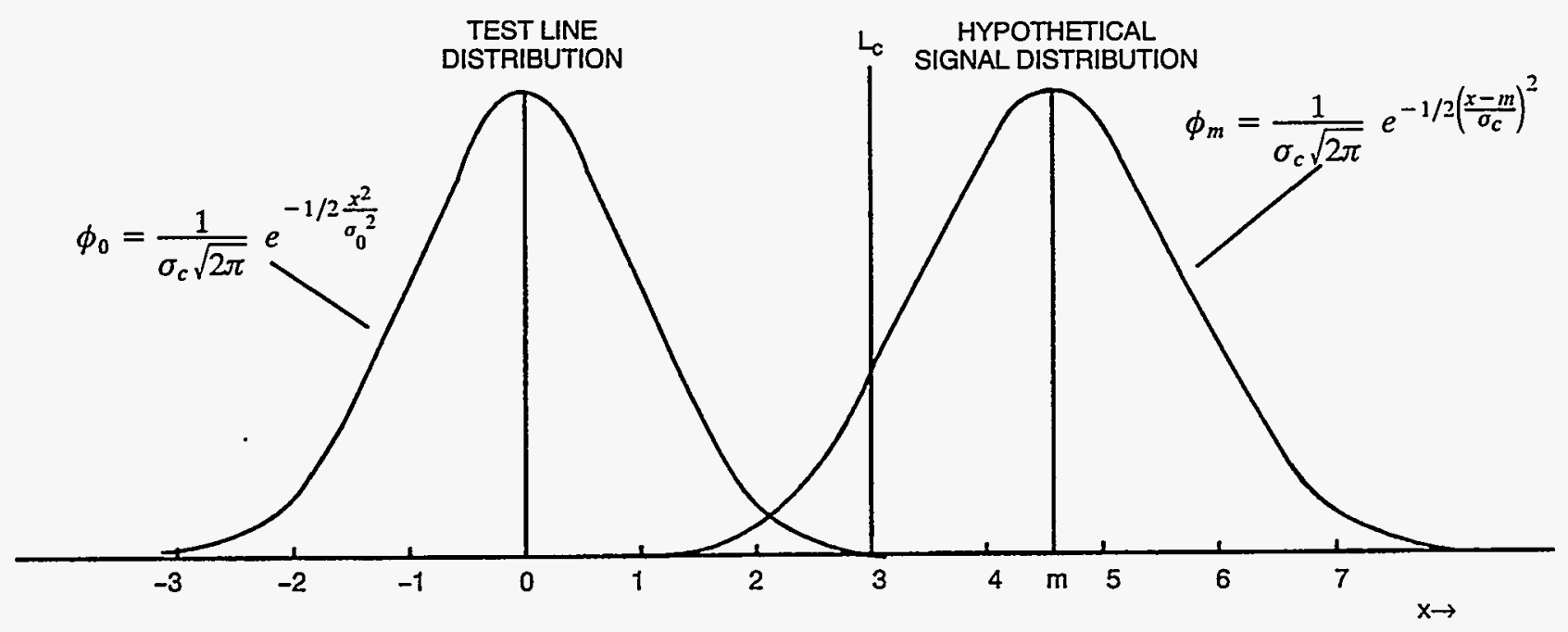

FIGURE 5. DISTRIBUTION FOR SIGNAL $=O$ AND SIGNAL $=m$

$90 \%$ of its area is above $L_{c}$, since only count rates above $L_{c}$ are investigated. The count rate of this hypothetical signal can then be calculated from the following two conditions:

$$
\begin{gathered}
\left(m-L_{c}\right) / \sigma_{c}=1.28 \\
\sigma_{c}^{2}=\sigma_{0}^{2}+m
\end{gathered}
$$

Using the quadratic formula to solve for $m$ results in:

$$
m=L_{c}+(1.28)^{2} / 2+1.28 \sqrt{L_{c}+\sigma_{0}^{2}}
$$

For the zero distribution, $\sigma_{0}=11$, and choosing $L_{c}=3 \sigma_{0}$ gives:

$$
m=49.7 \text { and } \sigma_{c}=13.1
$$

Table 1 lists probabilities of detection for several magnitudes of signal when $L_{c}=3 \sigma_{0}$. Also listed are the ${ }^{137} \mathrm{Cs}$ soil concentrations required to give the signals.
These were calculated using expressions derived by Beck. $^{12}$

\subsection{Ground-Based Measurements}

Table 2 lists the results of ground-based measurements made independently of the aerial measurements. The first column shows the sampling sites. The second column represents the aerial measurements. The third column shows exposure rates measured with an ion chamber. The fourth column represents the exposure rates calculated from photon counting by an Intrinsic Germanium Detector.

\subsection{CONCLUSIONS}

An aerial radiological survey was conducted in June 1993 over Project Rio Blanco and surrounding areas. The purpose of the aerial survey was to detect and document any anomalous gamma radiation in the environment which may have been caused as a result of an underground nuclear detonation in June 1972. The exposure rates measured within the survey regions were generally uniform and typical of rates resulting from natural background radiation. The average agreement of the aerial and ground-based measurements is six percent. No evidence of ${ }^{137} \mathrm{Cs}$ or any other man-made radionuclide was found. 


\begin{tabular}{|c|c|c|c|}
\hline \multicolumn{3}{|c|}{ Table 1. Cesium-137 Detection Probabilities } \\
\hline \multirow{2}{*}{$\begin{array}{c}\text { Detection } \\
\text { Probability }\end{array}$} & $\begin{array}{c}\text { Signala,b } \\
\pm \text { S.D. }\end{array}$ & \multicolumn{2}{|c|}{${ }^{137}$ Cs Concentrations $^{c}$} \\
\cline { 3 - 4 } & nCi/sq m & pCi/g \\
\hline $50 \%$ & $33 \pm 12$ & $43 \pm 16$ & $.92 \pm .33$ \\
$90 \%$ & $50 \pm 13$ & $65 \pm 17$ & $1.39 \pm .36$ \\
$95 \%$ & $55 \pm 13$ & $72 \pm 17$ & $1.53 \pm .36$ \\
$99 \%$ & $65 \pm 14$ & $85 \pm 18$ & $1.81 \pm .39$ \\
$99.9 \%$ & $76 \pm 14$ & $99 \pm 18$ & $2.11 \pm .39$ \\
\hline
\end{tabular}

a Signal was multiplied by 1.6 to compensate for the signal window being too narrow to contain the whole peak.

b Data averaged within 500-ft grid units.

c Soil distribution is assumed to be $\exp (-z / 3)$ where $z$ is the soil depth in $\mathrm{cm}$.

\begin{tabular}{|c|c|c|c|}
\hline Table 2. & \multicolumn{3}{|c|}{$\begin{array}{c}\text { Comparison of Aerial and Ground-Based Exposure } \\
\text { Rates }\end{array}$} \\
\cline { 2 - 4 } & \multicolumn{3}{|c|}{ Exposure Rate in $\mu \mathrm{R} / \mathrm{h} \pm$ Std. Dev. } \\
\cline { 2 - 4 } Location & Aerial $\mathrm{a}, \mathrm{b}$ & $\begin{array}{c}\text { lon } \\
\text { Chamber }\end{array}$ & $\begin{array}{c}\text { Soil Analysis } \\
\text { Estimate d,e }\end{array}$ \\
\hline 1 & $16.2 \pm 0.6$ & $16.8 \pm 0.8$ & $16 \pm 2$ \\
2 & $15.5 \pm 0.3$ & $17.4 \pm 1.0$ & $18 \pm 4$ \\
3 & $19.1 \pm 0.5$ & $18.8 \pm 0.9$ & $18 \pm 1$ \\
4 & $15.3 \pm 0.6$ & $16.4 \pm 0.8$ & $15.4 \pm 0.7$ \\
\hline
\end{tabular}

a Estimate includes a cosmic ray contribution of $7.0 \mu \mathrm{R} / \mathrm{h}$.

b Measured from a 1000- $\times 1000$-ft area centered on site.

c Reuter-Stokes PIC Model \#RSS-112, Serial\# G-003.

dEstimate includes a moisture correction of the form $1 /(1+\mathrm{m})$.

estimate includes a cosmic ray contribution of 7.0-7.3 $\mu \mathrm{R} / \mathrm{h}$, depending on elevation. 
APPENDIX A

\section{SURVEY PARAMETERS}

Survey Site:

Base of Operation:

Survey Dates:

Project Scientist::

Site Elevation:

Survey Altitude:

Line Spacing:

Aircraft Speed:

Survey Area:

Line Direction:

Detector Arrays:

Acquisition System:

Aircraft:

Navigation System:
52 miles north of Grand Junction, Colorado

Riffe, Colorado

June 3-11, 1993

L.V. Singman

$7,300-7,800 \mathrm{ft}$

$150 \mathrm{ft}(46 \mathrm{~m})$

$250 \mathrm{ft}(76 \mathrm{~m})$

70 knots $(36 \mathrm{~m} / \mathrm{s})$

$6 \times 2 \mathrm{mi}(10 \times 3 \mathrm{~km})$

Northeast-Southwest

Eight 2- $\times 4-\times 16$-in $\mathrm{Nal}(\mathrm{Tl})$

One 2- $\times 4-\times 4$-in Nal $(\mathrm{T} \ell)$

REDAR IV

MBB BO-105 helicopter, Tail No. N50EG

Differential Global Positioning System 


\section{APPENDIX B}

\section{GLOBAL POSITIONING SYSTEM}

The Global Positioning System (GPS) Differential Mode: The errors of GPS were reduced by using the differential mode. These errors are due to natural phenomena plus an intentionally introduced variable offset. The deliberate error is the most serious, varying over time from zero to $300 \mathrm{~m}$. Differential GPS operates by placing one receiver in the helicopter and another in a known stationary position. The difference between the known stationary position and its GPS reading is the GPS error at the time the signal was received. By continuously tracking the GPS signal, the error was known at any time. Error correction parameters were transmitted to the receiver in the helicopter.

GPS Dropouts: At times the intervening terrain prevented the differential signal from reaching the helicopter over a period of several seconds or more. The helicopter GPS receiver then fell back to the uncorrected GPS. Positions were corrected later by linearly interpolating between differentially corrected positions preceding and following dropouts. To make these dropouts obvious, the nondifferential positions were offset by one arc-minute in both latitude and longitude, which is roughly a mile in both directions. In this way, whenever the receiver lost the differential signal, the traced position of the helicopter on the computer-generated plot suddenly jumped approximately one mile, an obvious error.

Moving the GPS Unit: The stationary GPS receiver was placed on a hill overlooking the survey area at a distance of about six miles. The receiver had to be moved to cover a portion of the survey area because a ridge was blocking the differential signal from the helicopter. (As long as the position of our stationary receiver remained the same, it was not necessary to know the absolute position of the stationary receiver since all points within the survey area would be equally affected by an error in initial receiver placement.) To relate the first receiver position to the second, a common point was marked with the reference receiver in both positions. The two readings could have been off by $600 \mathrm{~m}$ in the worst case. Surprisingly, the difference was only $20 \mathrm{~m}$, which was about the estimated error made by the pilot in marking the position. No correction was deemed necessary. 


\section{APPENDIX C}

\section{ALTITUDE PROFILE}

The following calculation is routinely made in aerial surveys to correct for air absorption and nonterrestrial background. The nonterrestrial background was assumed to be due to gamma rays coming from three sources: space (cosmic rays), radon in the air, and naturally radioactive materials in the aircraft. It was experimentally determined as described below.

The total count rate was measured with the helicopter flying the same flight line at six different altitudes ranging from 150 to $3,000 \mathrm{ft}$ ( 46 to $1,000 \mathrm{~m}$ ). The measurements were fitted to an equation of the form:

$$
M(A)=B+T(150) \times e^{-u(A-150)}
$$

where $M(A)$ is the measured count rate at altitude $A$, $B$ is the nonterrestrial background, $\mathrm{T}(150)$ is the terrestrial count rate at the $150-\mathrm{ft}$ altitude, and $u$ is the air absorption coefficient in units of inverse feet. The $3,000-\mathrm{ft}$ measurement was taken as an initial approximation of the nonterrestrial background, since the absorption by the 3,000 feet of air renders the second term of the equation effectively zero. When the background determined in this way was subtracted from the measured values and the logarithm of the differences plotted against altitude, the result was a straight line with its slope equal to the air absorption coefficient, $u$.

Final values of $u$ and $B$ were obtained by adjusting them until the measured values made the best fit to a straight line as determined by the least squares method. 


\section{REFERENCES}

1. Luetkehans, G.R., J. Toman, R.M. Pastore, and D.B. DiBona. The Rio Blanco Experiment-Its Objectives, Design and Execution. Atomic Energy Commission, 1973.

2. Placque on Rio Blanco Ground Zero Monument.

3. Tipton, W.J. An Aerial Radiological Survey of Areas 25 and 26, Nevada Test Site, Date of Survey: September 1976, Report No. EGG-1183-1745. EG\&G/EM, Las Vegas, Nevada, 1979.

4. Feimster, E.L. An Aerial Radiological Survey of Areas 1, 2, 3, 4, 6, 7, 8, 9, 10, 12, 15 \& 17, Yucca Flat, Nevada Test Site, Date of Survey: 8 August-2 September 1978, Report No. EGG-1183-1808. EG\&G/EM, Las Vegas, Nevada, 1982.

5. Feimster, E.L. An Aerial Radiological Survey of Areas 18 and 20, Nevada Test Site, Date of Survey: October-November 1980, Report No. EGG-10282-1093. EG\&G/EM, Las Vegas, Nevada, 1985.

6. Clark, H.W. An Aerial Radiological Survey of Area 11, Nevada Test Site, Date of Survey: January 1982 , Report No. EGG-10282-1004. EG\&G/EM, Las Vegas, Nevada, 1983.

7. Bluitt, C.M. An Aerial Radiological Survey of Areas 16 and 30, Nevada Test Site, Date of Survey: June 1983, Report No. EGG-10282-1118. EG\&G/EM, Las Vegas, Nevada, 1986.

8. Jobst, J.E. An Aerial Radiological Survey of Areas 12, 15, 17 and 19, Nevada Test Site, Date of Survey: October-November 1984, Report No. EGG-10282-1113. EG\&G/EM, Las Vegas, Nevada, 1986.

9. Jaffey, A.H. "Statistical Tests for Counting." Nucleonics, Vol. 18, No. 11, 1960.

10. Currie, L.A. "Limits for Qualitative and Quantitative Determination." Analytical Chemistry, Vol. 40, No. 3,1968 .

11. Evans, R.D. The Atomic Nucleus. McGraw Hill, New York, New York, 1955, p 764.

12. Beck, H.L., J. DeCampo, and C. Gogolak. In Situ Ge(Li) and NaI(Tl) Gamma Ray Spectrometry, Report No. HASL-258, TID-4500. AEC Health and Safety Laboratory, New York, New York, 1972. 
DOE/DP

L.E. Gordon-Hagerty

O.W. Taylor

(1)

(1)

DOE/HQ

OSTI

DOE/NV

K. J. Cabble

M.R. Dockter

C.A. Santilli

(3)

(1)

(1)
DOE/NSIC

R.S. Scott

(3)

\section{EG\&G/EM}

J.F. Doyle LVAO

(1)

G.R. Shipman WAMO (1)

L.V. Singman LVAO (1)

W.J. Tipton LVAO (1)

P.H. Zavattaro LVAO (1)

\section{LIBRARIES}

RSL

TIC

AN AERIAL RADIOLOGICAL SURVEY OF

PROJECT RIO BLANCO

AND SURROUNDING AREA

NORTHWESTERN COLORADO EGG 11265-1057

DATE OF SURVEY: JULY 1993

DATE OF REPORT: NOVEMBER 1994 